feet. In accord with the peat-like alluvium out of which they are excavated and constructed, their colour is a dark ashen grey or nearly black. A distinctive feature of these meridian ants' nests is their highly ornate architectural style. They consist of a congeries of slender pinnacles erected close to one another in the same straight line, and which are finally amalgamated. Upon these primary pinnacles numerous subsidiary ones are usuaily constructed. The completed edifice, with its full complement of spires and pinnacles, comes thus when viewed end on, as shown in certain of the photographs taken, to present in miniature a by no means remote resemblance to the architectural pile of some grand cathedral.

A second and simpler form of meridian ants' nest is especially abundant a few miles inland from Port Darwin. It differs from the preceding type in its more massive and less ornate structural plan. The upper edge is nearly smooth or irregularly serrated, but not produced into a series of slender pinnacles. It is further noteworthy, that the environments pertaining to these two meridian varieties differ materially. With the Port Darwin type the habitat affected is that of open grassy plains, while in the Laura Valley form the nest mounds are most abundantly constructed in typical, though thinly wooded forest land.

The raison dêtre of the north and south directions of the longer axial planes, so eminently characteristic of the so-called "Meridian" ants' nests, has given rise to much speculation and a variety of interpretations. By some it is supposed to bear a direct relationship to the prevailing winds. As, however, those in the districts where these ant-hills occur are chiefly south-east or north-west, according to the seasonal monsoon, that interpretation cannot be accepted as satisfactory. To the writer's mind a more probable explanation would appear to present itself in connection with the circumstance that being constructed in this precise meridian line, their larger surface presents the least possibly prolonged exposure to the meridianal ravs of the tropical sun, and that the structures are consequently so built that they shall absorb and retain a minimum amount of solar heat. This question is, however, an interesting one that undoubtedly invites further scientific investigation. The subject of Australian termitaria constitutes, it may be noted, a copiously illustrated chapter in the writer's recently published work, "The Naturalist in Australia."

W. SAVILLE-KENT.

\section{THE LIQUEFACTION OF FLUORINE.}

FLUORINE was prepared for the first time in I 886 by Prof. Moissan, as a product of the electrolysis of anhydrous hydrogen fluoride contained in a platinum apparatus provided with fluorspar stoppers; the new gas was at once found to be the most active chemical substance known, many elements and organic compounds, such as arsenic, antimony, sulphur, iodine, alcohol, and turpentine, immediately and spontaneously bursting into flame when plunged into an atmosphere of fluorine. On mixing the gas with hydrogen, even in the dark, a violent detonation immediately occurs; hydrogen fluoride being produced. The violent action of fluorine upon nearly all substances with which it is brought into contact, obviously renders extremely difficult all experimental work involving the use of the free element. The great manipulative difficulties necessarily arising whilst dealing with the gas on the large scale have, however, been very happily surmounted by Prof. Moissan and Prof. Dewar, who recently described to the Chemical Society the method by which they have succeeded in liquefying fluorine, and determining the more important properties of the liquid substance (Proc. Chem. Soc., November 4, 1897, p. 175). It seemed likely that the great chemical activity of fluorine might so far decrease at low temperatures as to allow of the manipulation of the material in a glass vessel cooled in liquid air ; this was found to be the case.

The fluorine required in the work was prepared by the electrolysis of anhydrous hydrogen fluoride; this liquid being a non-conductor, was made a conductor by dissolving in it potassium fluoride. The liberated fluorine was freed from hydrogen fluoride by being passed first through a platinum worm immersed in a cooling mixture of solid carbon dioxide and alcohol, and subsequently through platinum tubes containing dry sodium fluoride. The purified gas was then passed down a vertical platinum tube fused to the neck of a thin glass bulb which served as the collector, and an exit was provided through a narrower platinum tube contained inside the first. On cooling the apparatus down to $-183^{\circ}$ in boiling oxygen whilst the fluorine is passing through, no liquefaction occurs, but on reducing the pressure under which the oxygen is boiling, and so lowering the temperature to $-185^{\circ}$, the fluorine condenses in the glass bulb to a very mobile yellow liquid; on removing the bulb from the cooling bath the liquid fluorine boils vigorously. Other experiments made with boiling liquid oxygen and liquid air as refrigerating agents indicated that fluorine boils at about - $187^{\circ}$, namely at the boiling point of liquid argon; from this the probable critical temperature and pressure of fluorine are deduced as $-120^{\circ}$ and 40 atmospheres respectively.

At these low temperatures fluorine is without action on glass, and does not displace iodine from iodides; silicon, boron, carbon, sulphur, phosphorus and reduced iron, all of which spontaneously ignite when brought into contact with fluorine at ordinary temperatures, do not inflame if, after being cooled in liquid oxygen, they are plunged into an atmosphere of fluorine. Hydrogen gas inflames spontaneously, with considerable evolution of light and heat, when directed on to the surface of liquid fluorine at $-190^{\circ}$; on passing fluorine on to solidified turpentine cooled by boiling liquid air, a series of explosions occurred resulting in the destruction of the apparatus. It thus seems that the great affinity existing between hydrogen and fluorine is not overcome at - I90. A little liquid fluorine falling on the floor instantly inflames the wood. Fluorine is soluble in liquid oxygen, and on passing in the gas a white flocculent precipitate is formed which, after filtering off, deflagrates violently as the temperature rises; it is possibly a hydrate of fluorine.

Determinations made by floating pieces of various substances in liquid fluorine indicate that its density is about I.I4, and from the invisibility of amber immersed in the liquid the refractive index of the latter would seem to be higher than that of liquid air or oxygen. Liquid fluorine shows no magnetic phenomena when placed between the poles of a powerful electromagnet ; it has a smaller capillarity constant than liquid oxygen, and does not solidify at $-210^{\circ}$. It has no absorption spectrum, and its colour is the same as that of the gaseous element.

W. J. P.

\section{THE LEONID DISPLAY, 1897.}

VERY unfavourable weather appears to have prevented the successful observation of the Leonids at their recent return. In consequence of this the impression seems to have gained ground that the phenomenon did not occur as predicted. This is, however, a mistake. Could those observers who saw so little on the night of the 13 th, have viewed the sky late on the following night, they must have been satisfied at the character of the display. Between about 4.30 and 6 a.m. on Monday morning the 15 th, the usual streak-leaving meteors from Leo became very numerous, and some of them were unusually brilliant, one, which

No. $146_{5}$, VOL. 57$]$ 
appeared at 5.25 a.m., being brighter than the moon. Unfortunately the sky was overcast at the great majority of places at the time when the maximum occurred, and very few reports have come to hand, but they furnish unquestionable evidence as to a plentiful fall of meteors in the few hours preceding sunrise on the 15 th.

Before midnight on the $13^{\text {th }}$, and during the early morning hours of the 14 th, meteors were comparatively rare, and may be said to have been more conspicuous by their absence than by their presence. The shower of Leonids was of an extremely meagre character, and such as might occur in an ordinary year with the parent comet near its aphelion. But, apart from the disappointing meteors, the night of the 13th was one of singular beauty. At Bristol the sky partly cleared at II.30 p.m., and the atmosphere became remarkably transparent. The moon and stars shone very brightly, and films of white cloud, floating rapidly across the sky, gave it a very picturesque appearance.

From the observations reported it may be well to make a few extracts :-

Mr. S. H. R. Salmon, South Croydon.-Sky perfectly clear November 13, 14h. to $16 \mathrm{~h}$. About seven meteors seen, including four bright ones as under :

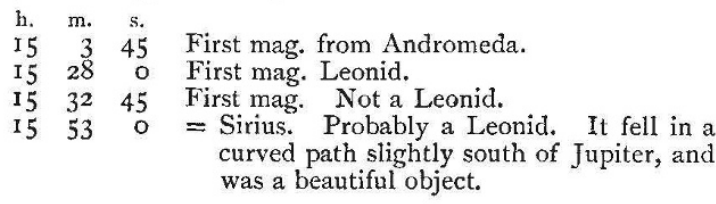

Rev. S. J. Johnson, Bridport.-Tolerably clear on Noyember I3, between I5h. and I5h. 3om., but not a single meteor was observed.

Miss Brown, Cirencester.-The sky was perfectly clear on November I 3, I I h. $45 \mathrm{~m}$. to I3 h. I $5 \mathrm{~m}$., and the eastern sky was watched from a window facing that quarter, but no meteors were seen.

Mr. W. H. Milligan, Belfast.-Cloudy weather prevented observation except on one night, November I3, II h. to I2h. 3om., when only one sporadic meteor was recorded; no Leonids.

D. W: Walton, Kingston-on-Thames.-Sky clear and moon bright on November I3, IOh. 30m. to I Ih. 3om., but only one meteor appeared. Partly overcast afterwards, but a few faint meteors were noticed in breaks between the clouds.

Bristol.-The writer watched the sky on November I 3 , between about $\mathrm{I} \mathrm{Ih}$. $30 \mathrm{~m}$. and I $3 \mathrm{~h}$., but no Leonids were recorded. The sky clouded after I $4 \mathrm{~h}$., and the following night was overcast throughout. Mr. Corder, at Bridgwater, reports that the nights following November I 3 and I 4 were too cloudy to permit of observation.

W. Trueman Tucker, Loughborough.-On November I4 the clouds cleared away between I6h. and I6h. 30m., but the moon was very bright, and must have extinguished many of the smaller meteors. Between I6h. 3om. and I8h. a considerable number of shooting stars were observed, but no exact count was kept. The lines and approximate paths of ten of the more conspicuous ones were noted, and the brightest of all appeared in Cepheus at $17 \mathrm{~h} .25 \mathrm{~m}$. It was sufficiently luminous to cast distinct shadows in spite of the moonlight. Very brilliant meteors also fell at $17 \mathrm{~h}$. Iom., $17 \mathrm{~h} .15 \mathrm{~m} ., 17 \mathrm{~h} .35 \mathrm{~m}$. and $17 \mathrm{~h} .40 \mathrm{~m}$.

The Dumfries and Galloway Standard of November 17 reports that the nights of November 12 and 13 were overcast. On November 14 , soon after midnight, the clouds began to roll off, and the sky afterwards became very clear. An amateur observer began watching at I $2 \mathrm{~h}$. 3om., and from that time until $16 \mathrm{~h}$. $15 \mathrm{~m}$. he noted in all only thirty-three meteors, not more than thirteen or fourteen being Leonids. He then, thinking the outlook not sufficiently promising for any striking develop- ment of the shower, folded up his note book and star charts and retired. Shortly afterwards, however, the Leonids increased rapidly both in numbers and brilliancy. At about $16 \mathrm{~h}$. 50m. "a couple of young bakers going along the Whitesands to their work, were startled by many meteors throwing their fiery lances athwart the sky. They estimate the numbers as not fewer than ten shooting stars to the minute, and state they never saw so many before in all their lives."

The latter description is probably exaggerated, but it seems to convey an expression of fact such as we should expect from persons not acquainted with, but surprised by, an unusual celestial event. Though the rough estimate given as to the number of meteors visible may far exceed the actual figures, there is no doubt from the corroborative testimony afforded by $\mathrm{Mr}$. Tucker at Loughborough, quoted in a previous paragraph, that the Leonid shower displayed quite a special activity on the morning of November I5. That it was apparently observed by few persons is unfortunate, but no other result could be expected in view of the cloud-laden atmosphere which prevailed, generally, at the time. It is to be hoped that more favourable conditions obtained at foreign stations, and that successful observations were secured. The shower seems to have presented itself somewhat later than the time expected, both in 1896 and I 897.

W. F. DENNING.

\section{FORSTER HEDDLE, M.D.}

FARLY on the morning of November I9 there passed away at St. Andrews the foremost mineralogist of Scotland, and one of the most distinguished in the United Kingdom.

Matthew Forster Heddle was the younger son of Robert Heddle, Esq., of Melsettar, in Orkney, and was born in I828. In 1844 he went to the University of Edinburgh, where he studied medicine and attended the classes of Gregory and Jameson. Even at this time his tastes lay in the direction of science ; and on the completion of his medical studies he proceeded to Germany, where he devoted himself to chemistry and mineralogy, at first in Clausthal and afterwards under the illustrious Breithaupt at Freiburg. Returning to Edinburgh, he took his degree as Doctor of Medicine in $185 \mathrm{I}$, his graduation thesis being a treatise "On the Ores of the Metals."

He practised for a short time in Edinburgh, but never found this occupation a congenial one, devoting by degrees all his time to analysis and other scientific work. In 1856 he organised an expedition to the Faroe Islands. Five months of the summer of that year were spent in a mineralogical survey of the group, resulting in large additions to his cabinet, and putting on a firm foundation his knowledge of the mode of occurrence of the zeolites of the tertiary volcanoes.

On Dr. Heddle's return from this expedition he was appointed assistant to Prof. Connell at the University of St. Andrews, and on Connell's death, in I862, he succeeded him as Professor of Chemistry, occupying this chair for twenty-two years. He threw himself with characteristic energy into his work at the University, spending a very considerable part of his salary in the purchase and fitting up of the apparatus for his experiments.

$\mathrm{He}$ found time, however, during these years for much mineralogical work, in the course of which he again and again traversed the whole North of Scotland and the Western Islands, thus acquiring an unrivalled acquaintance with its rocks and minerals. The results of these explorations were embodied in a series of papers read principally before the Royal Society of Edinburgh, of which he was, in 1878 , elected a Fellow, and the Mineralogical Society, of which he was one of the 